\title{
Myasthenia gravis: past, present, and future
}

\author{
Bianca M. Conti-Fine, ${ }^{1}$ Monica Milani, ${ }^{1}$ and Henry J. Kaminski²
}

${ }^{1}$ Department of Biochemistry, Molecular Biology, and Biophysics, University of Minnesota, Minneapolis, Minnesota, USA. ${ }^{2}$ Departments of Neurology and Neurosciences, Case Western Reserve University, Louis Stokes Cleveland Veterans Affairs Medical Center, Cleveland, Ohio, USA.

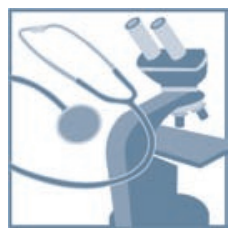

Myasthenia gravis (MG) is an autoimmune syndrome caused by the failure of neuromuscular transmission, which results from the binding of autoantibodies to proteins involved in signaling at the neuromuscular junction (NMJ). These proteins include the nicotinic AChR or, less frequently, a muscle-specific tyrosine kinase (MuSK) involved in AChR clustering. Much is known about the mechanisms that maintain self tolerance and modulate anti-AChR Ab synthesis, AChR clustering, and AChR function as well as those that cause neuromuscular transmission failure upon $\mathrm{Ab}$ binding. This insight has led to the development of improved diagnostic methods and to the design of specific immunosuppressive or immunomodulatory treatments.

Acquired myasthenia gravis (MG) is an uncommon disorder (200-400 cases per million; ref. 1). Its symptoms are caused by a characteristic muscle weakness that worsens after use of affected muscles. In about two-thirds of patients, the extrinsic ocular muscles (EOMs) present the initial symptoms. The symptoms usually progress to the other bulbar muscles and limb muscles, resulting in generalized MG (gMG). In about $10 \%$ of MG patients, symptoms remain limited to the EOM, and this condition is termed ocular MG (oMG).

MG fulfills the strict criteria of an Ab-mediated autoimmune disorder: (a) Abs are present at the site of pathology, the neuromuscular junction (NMJ); (b) Ig from MG patients or anti-AChR Abs from experimental animals cause MG symptoms when injected into rodents; (c) immunization of animals with AChR reproduces the disease; and (d) therapies that remove Abs decrease the severity of MG symptoms.

\section{Historical perspective}

The first described case of MG is likely that of the Native American Chief Opechancanough, who died in 1664, as reported by Virginian chroniclers: "The excessive fatigue he encountered wrecked his constitution; his flesh became macerated; his sinews lost their tone and elasticity; and his eyelids were so heavy that he could not see unless they were lifted up by his attendants ... he was unable to walk; but his spirit rising above the ruins of his body directed from the litter on which he was carried by his Indians" (2). In 1672, the English physician Thomas Willis described a patient with the "fatiguable weakness" of limbs and bulbar muscles characteristic of MG (3). In the late 1800s, the first modern descriptions of patients with myasthenic symptoms were published (3), and the name myasthenia gravis was coined by fusing the Greek terms for muscle and weakness to yield the noun myasthenia and adding the Latin adjective gravis, which means severe (4).

Attempts at rational treatments of MG began in the 1930s. A major step forward occurred in 1934 when Mary Walker realized that MG symptoms were similar to those of curare poisoning,

Nonstandard abbreviations used: AChE, acetylcholinesterase; APL, altered peptide ligand; EAMG, experimental autoimmune MG; EOM, extrinsic ocular muscle; EPP, endplate potential; gMG, generalized MG; IVIg, intravenous Ig; MG, myasthenia gravis; MuSK, muscle-specific tyrosine kinase; NMJ, neuromuscular junction; oMG, ocular MG.

Conflict of interest: The authors have declared that no conflict of interest exists. Citation for this article: J. Clin. Invest. 116:2843-2854 (2006). doi:10.1172/JCI29894. which was treated with physostigmine, a cholinesterase inhibitor. She showed that physostigmine promptly improved myasthenic symptoms (5), making anticholinesterase drugs a staple in MG management. Because thymus pathology is common in MG patients, as first noted in the late 1800s (3), in 1937, Blalock removed a mediastinal mass from a young woman who had MG (3); the patient improved postoperatively. Later, Blalock reported other myasthenic patients who improved after thymus removal (3), establishing thymectomy as a treatment for MG.

In 1959-1960, Simpson and Nastuck proposed independently that MG has an autoimmune etiology $(6,7)$ based on several observations: (a) MG patients' sera compromise contraction in nervemuscle preparations; (b) the level of serum complement correlates inversely with the severity of MG symptoms; (c) infants of myasthenic mothers may present transient myasthenic symptoms (neonatal MG); (d) inflammatory infiltrates may occur in muscles of MG patients, and pathologic changes are common in their thymi; and (e) MG may be associated with other putative autoimmune disorders.

In 1973, Patrick and Lindstrom demonstrated that rabbits immunized with purified muscle-like AChR developed MG-like symptoms (experimental autoimmune MG [EAMG]) (8). After that seminal discovery, many studies demonstrated an autoimmune response against muscle AChR in MG and the role of anti-AChR Abs in causing the structural and functional damage of the NMJ. These findings promoted the use of immunosuppressants in MG. In the 1970s, prednisone and azathioprine became established treatments for MG (9), and plasma exchange was introduced as an effective acute treatment for severe MG (10), further proving that circulating factors caused MG symptoms.

\section{Pathogenesis of MG: current state of the art}

Structure and function of the NMJ. The terminal arborization of $\alpha$-motor neuron axons from the ventral horns of the spinal cord and brainstem provides the nerve terminals that form the NMJ (Figure 1). These myelinated axons reach the muscles through peripheral nerves; then each axon divides into branches that innervate many individual muscle fibers. As it approaches its target fiber, each branch loses the myelin sheath and further subdivides into many presynaptic boutons, which contain ACh-loaded synaptic vesicles and face the surface of the muscle fiber at the NMJ (Figure 1). The synaptic bouton and the muscle surface are separated by the synaptic cleft, a $20 \mathrm{~nm}$-thick space that contains acetylcholinesterase (AChE) and other proteins and proteoglycans involved in 


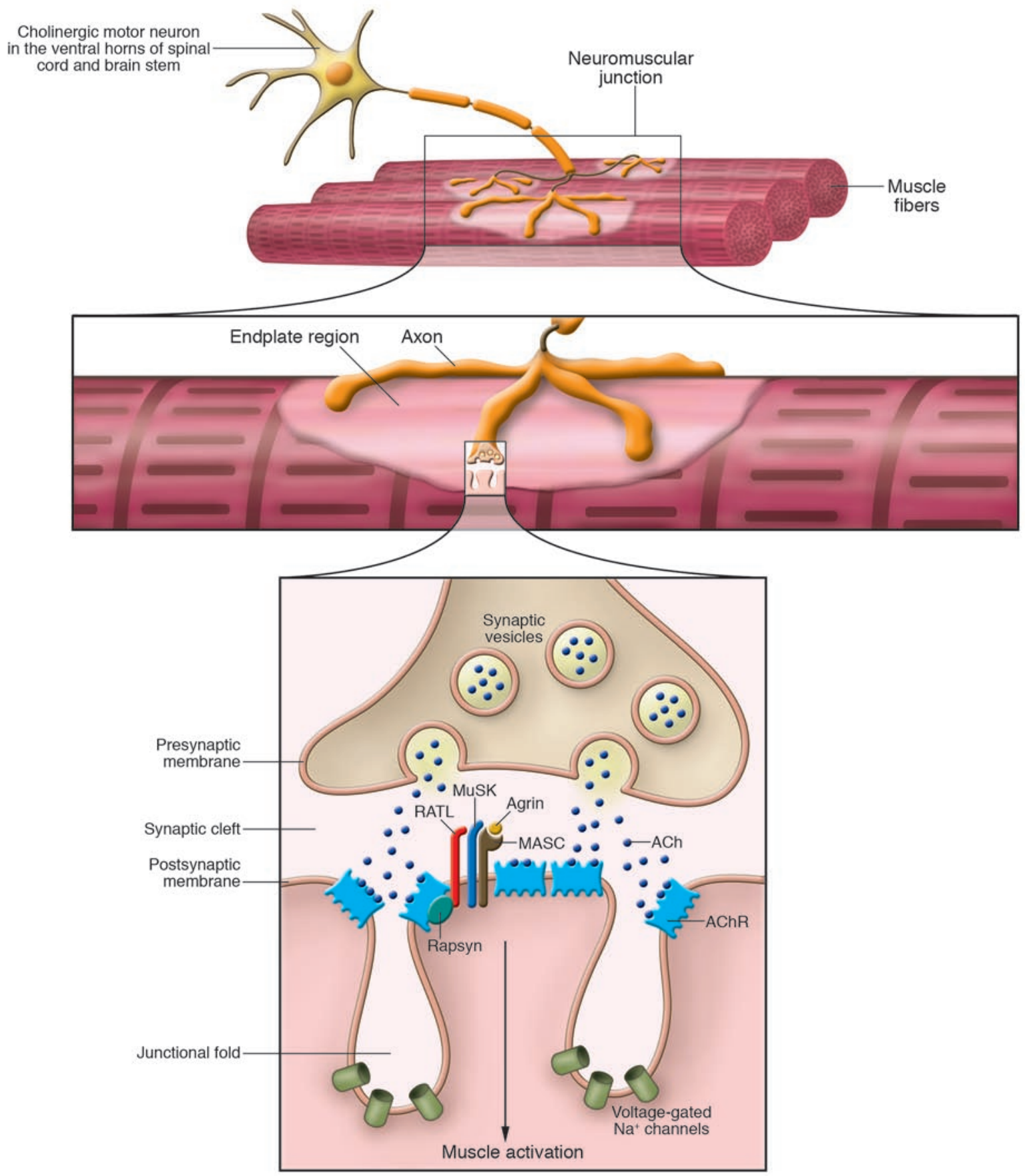

Figure 1

Structure of the NMJ. As it enters the muscle and approaches its target fibers, each $\alpha$-motor neuron axon divides into branches that innervate many individual muscle fibers. Each branch loses its myelin sheath and further subdivides into many presynaptic boutons, which contain AChloaded synaptic vesicles and face the surface of the muscle fiber at the NMJ. The synaptic bouton and the muscle surface are separated by the synaptic cleft, which contains AChE and proteins and proteoglycans involved in stabilizing the NMJ structure. The NMJ postsynaptic membrane has characteristic deep folds, and the AChR is densely packed at the fold top. When the nerve action potential reaches the synaptic bouton, ACh is released into the synaptic cleft, where it diffuses to reach and bind the AChR. ACh binding triggers the AChR ion channel opening, permitting influx of $\mathrm{Na}^{+}$into the muscle fiber. The resulting EPP activates voltage-gated $\mathrm{Na}^{+}$channels at the bottom of the folds, leading to further $\mathrm{Na}^{+}$influx and spreading of the action potential along the muscle fiber. Other proteins, including Rapsyn, MuSK, and agrin, which are involved in AChR clustering, are also present on the muscle membrane in close proximity to the AChR. MASC, myotube-associated specificity component; RATL, rapsyn-associated transmembrane linker. Figure modified with permission from Lippincott Williams and Wilkins (126). 
stabilizing the NMJ structure. The NMJ postsynaptic membrane has characteristic deep folds: the AChR is densely packed (about 12,000 molecules per $\mu \mathrm{m}^{2}$ ) in highly ordered hexagonal lattices of molecules at the tops of the folds.

Muscle AChR molecules are transmembrane proteins formed by 5 subunits: 2 identical $\alpha$ subunits, which contribute important structural elements to the ACh-binding sites, and 3 different but homologous subunits, termed $\beta, \gamma$ (or $\varepsilon$; see below), and $\delta$. Muscle expresses 2 developmentally regulated $\mathrm{AChR}$ isoforms. Embryonic muscle expresses AChRs formed by $\alpha, \beta, \gamma$, and $\delta$ subunits. After innervation, expression of the $\gamma$ subunit gene is substituted by that of the homologous $\varepsilon$ subunit gene to yield the adult AChR isoform, a complex of $\alpha, \beta, \delta$, and $\varepsilon$ subunits. Some adult muscles, notably the EOM, still express embryonic AChR (11).

When the nerve action potential reaches the synaptic bouton, the depolarization opens voltage-gated $\mathrm{Ca}^{2+}$ channels on the presynaptic membrane. This $\mathrm{Ca}^{2+}$ influx triggers fusion of synaptic vesicles with the presynaptic membrane and ACh release. Quantal content of a nerve impulse refers to the number of $A C h$ vesicles (quanta) released by that impulse. The ACh diffuses into the synaptic cleft (where it can be hydrolyzed by AChE) and reaches and binds to AChR, thereby triggering the opening of its cation channels and influx of $\mathrm{Na}^{+}$into the muscle fiber. The resulting endplate potential (EPP) activates voltage-gated $\mathrm{Na}^{+}$channels, leading to further influx of $\mathrm{Na}^{+}$and spreading of the action potential along the muscle fiber.

The postsynaptic transmembrane protein, muscle-specific tyrosine kinase (MuSK) (Figure 1), is the main autoantigen in some MG patients (12). MuSK expression in both developing and mature muscle is similar to that of AChR. In mature muscle, MuSK is present prominently only at the NMJ, where it is part of the receptor for agrin. Agrin is a protein synthesized by motor neurons and secreted into the synaptic basal lamina. The signaling mediated by agrin/MuSK interaction triggers and maintains rapsyn-dependent clustering of AChR and other postsynaptic proteins (13). Rapsyn, a peripheral membrane protein exposed on the cytoplasmic surface of the postsynaptic membrane, is necessary for clustering of AChR, with which it coclusters. Rapsyn and AChR are present in equimolar concentrations at the NMJ, and they may be physically associated. Rapsyn causes clustering of NMJ proteins other than the AChR, including MuSK. Mice lacking agrin or MuSK fail to form NMJs and die at birth of profound muscle weakness, and their AChR and other synaptic proteins are uniformly expressed along the muscle fibers (14).

NMJ properties that influence susceptibility to muscle weakness in $M G$. The EPP generated in normal NMJs is larger than the threshold needed to generate an action potential. This difference may vary in different muscles, as discussed below. Neuromuscular transmission safety factor is defined as the ratio between the actual EPP and the threshold potential required to generate the muscle action potential. Its reduction is the electrophysiological defect that causes MG symptoms.

The quantal content of an impulse, the conduction properties and density of postsynaptic AChR, and the activity of AChE in the synaptic cleft all contribute to the EPP (15). Also, the postsynaptic folds (Figure 1) form a high-resistance pathway that focuses endplate current flow on voltage-gated $\mathrm{Na}^{+}$channels in the depths of the folds, thereby enhancing the safety factor. A reduction in the number or activity of the AChR molecules at the NMJ decreases the EPP, which may still be adequate at rest; however, when the quantal release of ACh is reduced after repetitive activity, the EPP may fall below the threshold needed to trigger the action potential.
NMJ properties vary among muscles and may influence muscle susceptibility to MG (15). This is well illustrated by the NMJ of the EOMs, which are especially susceptible to developing myasthenic weakness. The NMJs of EOM differ from those of skeletal muscle in several ways. They have less prominent synaptic folds, and therefore fewer postsynaptic AChRs and $\mathrm{Na}^{+}$channels, and a reduced safety factor (16). They are subject to very high neuronal firing frequency, making them prone to fatigue. Also, they express less intrinsic complement regulators, making them more susceptible to complement-mediated injury (17). In skeletal muscles, fasttwitch fibers have NMJs with greater quantal contents, a greater degree of postsynaptic folding (18), and higher postsynaptic sensitivity to ACh than slow-twitch NMJs (19), and they have increased $\mathrm{Na}^{+}$current in the NMJ region (20). These properties may make fast-twitch skeletal muscle fibers less susceptible to myasthenic failure than slow-twitch fibers.

Effector mechanisms of anti-AChR Abs. Anti-AChR Abs affect neuromuscular transmission by at least 3 mechanisms: (a) binding and activation of complement at the NMJ; (b) accelerated degradation of AChR molecules crosslinked by Ab (a process known as antigenic modulation); and (c) functional AChR block (Figure 2).

The NMJs of MG patients and EAMG animals contain activation fragments of complement component 3 (C3), the terminal and lytic complement component 9 (C9), and the membrane attack complex (MAC) (21). Different lines of indirect evidence suggest that complement activation at the NMJ might be the primary cause of AChR loss and failure of neuromuscular transmission (Figure 2A): (a) complement depletion protects animals from EAMG (22); (b) administration of Abs that block complement component 6 (anti-C6) (23) or a complement inhibitor (soluble CR1) (24) protects rodents from EAMG; (c) mice with a reduced complement function because of a genetic deficit of complement components are resistant or less susceptible to EAMG induction than mice with normal complement (25); (d) IL-12-deficient mice, which synthesize Th1-driven, complement-fixing Abs poorly (26), develop minimal EAMG symptoms after AChR immunization in spite of robust anti-AChR Ab synthesis; moreover, their NMJs contain Abs but not complement, suggesting that anti-AChR Abs that do not activate complement do not effectively compromise neuromuscular transmission.

Cells are protected from activation of autologous complement on their surfaces by the so-called intrinsic complement regulators. These include the decay-accelerating factor (DAF or CD55), the membrane cofactor protein (MCP or CD46), and the membrane inhibitor of reactive lysis (MIRL or CD59) (27-29). Consistent with an important role of complement in EAMG, passive transfer of EAMG with anti-AChR Abs causes more severe muscle weakness in DAF-deficient mice than in wild-type mice (30).

Antigenic modulation is the ability of an Ab to cross-link 2 antigen molecules, thereby triggering a cellular signal that causes accelerated endocytosis and degradation of the cross-linked molecules (Figure $2 \mathrm{~B}$ ). IgG from MG patients causes antigenic modulation of muscle AChR in vivo and in vitro (31). If accelerated degradation is not compensated by increased AChR synthesis (32), it will lead to a reduction of the available AChR molecules at the NMJ and myasthenic symptoms. This property can be used as a diagnostic test for MG (32). However, not all anti-AChR Abs cause antigenic modulation because, even though all IgG Abs have 2 antigen-binding sites, the epitope location on the AChR surface may restrict the ability of Abs to cross-link a second AChR molecule (33). 
A Complement binding and activation at the NMJ

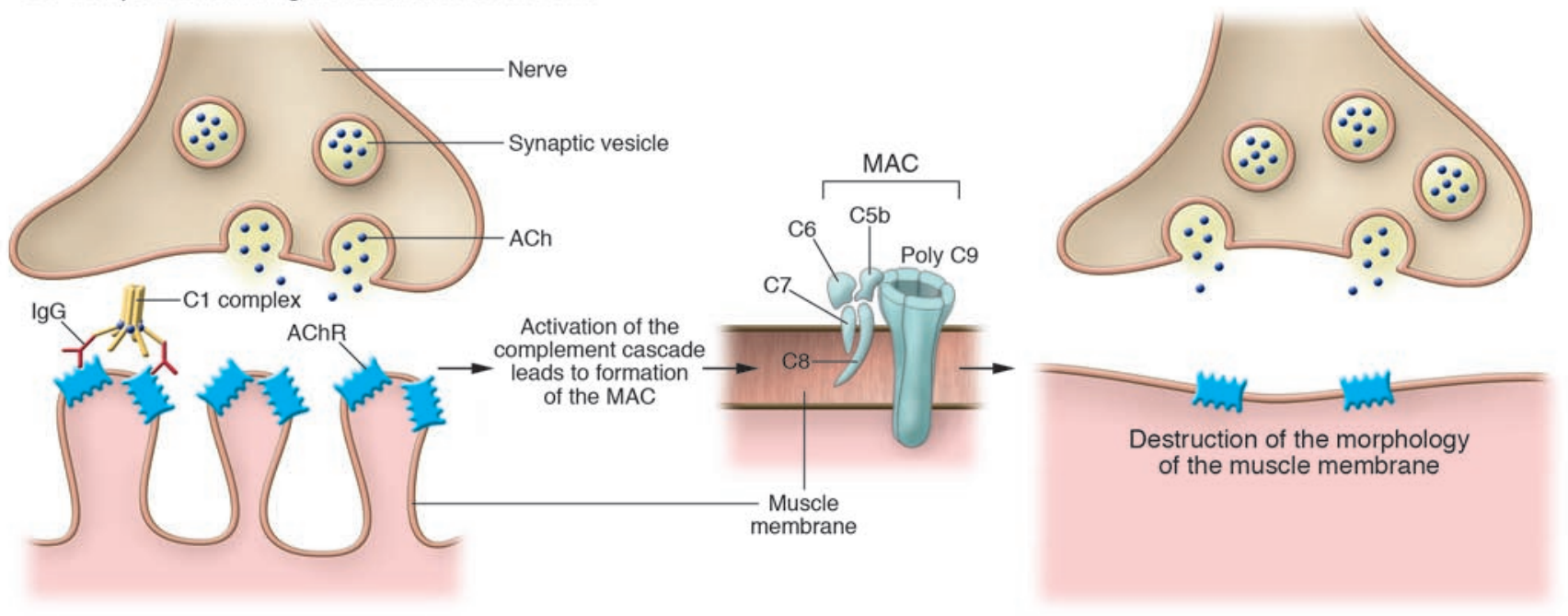

B Antigenic modulation

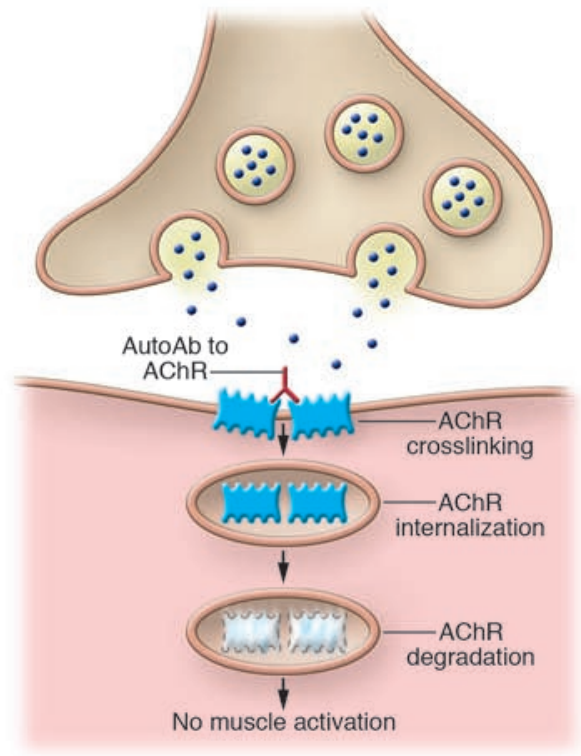

C Functional AChR block

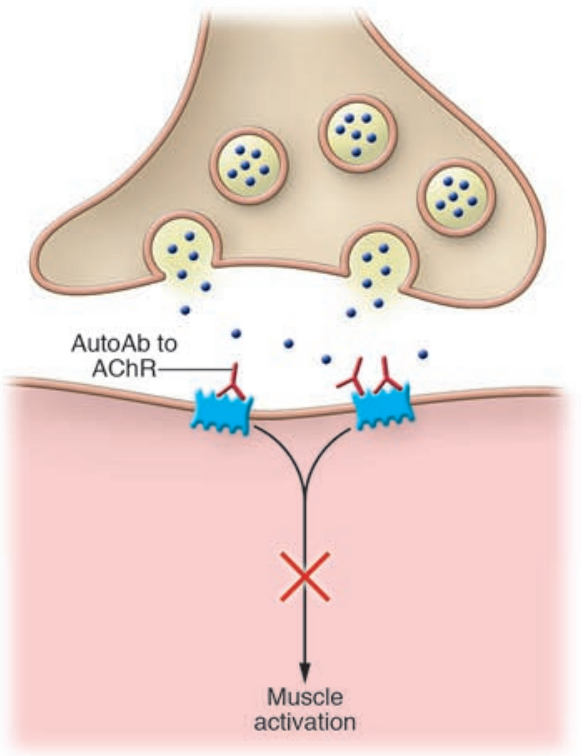

Figure 2

Effector mechanisms of anti-AChR Abs. (A) Ab binding to the AChR activates the complement cascade, resulting in the formation of membrane attack complex (MAC) and localized destruction of the postsynaptic NMJ membrane. This ultimately leads to a simplified, altered morphology of the postsynaptic membrane of the NMJ of MG patients, which lacks the normal deep folds and has a relatively flat surface. (B) Abs cross-link AChR molecules on the NMJ postsynaptic membrane, causing endocytosis of the cross-linked AChR molecules and their degradation (antigenic modulation). This ultimately leads to a reduced number of AChR molecules on the postsynaptic membrane. (C) Ab binding the ACh-binding sites of the AChR causes functional block of the AChR by interfering with binding of ACh released at the NMJ. This results in failure of neuromuscular transmission.

Functional AChR block due to Ab binding to the ACh-binding site (Figure 2C) is an uncommon pathogenic mechanism in MG, yet it may be clinically important. This is because the presence of $A b$ to the ACh-binding site of the AChR causes acute, severe muscle weakness in rodents without either inflammation or necrosis of the NMJ (34). Many MG patients have low levels of anti-AChR Abs that recognize the ACh-binding site (35); these might block the AChR in spite of their low concentration and contribute to acute myasthenic crises.

Role of $\mathrm{CD}^{+} \mathrm{T}$ cells in $\mathrm{MG}$. Pathogenic anti-AChR Abs are highaffinity IgGs, whose synthesis requires that activated $\mathrm{CD} 4^{+} \mathrm{T}$ cells interact with B cells, resulting in low-affinity anti-AChR Abs. This triggers somatic mutations of the Ig genes, leading to synthesis of high-affinity Abs. B cells secreting low-affinity anti-AChR Abs are common; for example, about $10 \%$ of monoclonal IgGs in multiple myeloma patients bind muscle AChRs (36). Myelomas are rarely associated with $\mathrm{MG}$, perhaps because of the low affinity of their anti-AChR Abs (36).

MG patients have AChR-specific $\mathrm{CD}^{+} \mathrm{T}$ cells with $\mathrm{T}$ helper function in the blood and thymus (37), and their symptoms improve after thymectomy (38) or treatment with anti-CD4 Abs 
(39). Moreover, in MG patients with AIDS, a reduction in $\mathrm{CD}^{+}$ $\mathrm{T}$ cells correlates with myasthenic symptom improvement (40). Studies in experimental systems directly demonstrated that $\mathrm{CD}^{+} \mathrm{T}$ cells are necessary for the development of MG symptoms. SCID mice engrafted with blood lymphocytes from MG patients produce anti-human AChR Abs and develop MG symptoms only if the grafted cells include $\mathrm{CD} 4^{+} \mathrm{T}$ cells (41). Also, mice genetically deficient in functional $\mathrm{CD}^{+} \mathrm{T}$ cells do not develop EAMG (42). Healthy subjects may have AChR-specific $\mathrm{CD}^{+} \mathrm{T}$ cells, which do not cause a clinically significant autoimmune response, probably because of mechanisms of immunological tolerance, which fail in autoimmunity.

Blood $\mathrm{CD}^{+} \mathrm{T}$ cells from both gMG and oMG patients respond to the AChR in vitro. Those from gMG patients respond to all the AChR subunits (43), and their epitope repertoire expands as the disease progresses (44). A few AChR sequences were recognized by most gMG patients (e.g., see ref. 45 ). $C D 4^{+} \mathrm{T}$ cell lines specific for these "universal" AChR epitopes, when grafted into SCID mice, support anti-AChR Ab production by B cells, which result in MG symptoms (41). The responses to AChR and AChR epitopes of $\mathrm{CD}^{+} \mathrm{T}$ cells from oMG patients were weaker and less stable over time than in those of gMG patients (44). Also, CD4 ${ }^{+} \mathrm{T}$ cells from individual oMG patients rarely recognize all AChR subunits, even when the disease has lasted for many years (44). It is not clear whether $\mathrm{CD}^{+} \mathrm{T}$ cells from oMG patients recognize the embryonic $\gamma$ or the adult $\varepsilon$ subunit or both (44).

The pathogenic role of anti-AChR CD4 $4^{+} \mathrm{T}$ cells in $\mathrm{MG}$ and EAMG explains the important role of MHC class II molecules, which present the antigen epitopes to the specific $\mathrm{CD}^{+} \mathrm{T}$ cells. In mice, susceptibility to EAMG correlates with the class II molecule alleles that they express (46). Moreover, a mutation of the gene encoding the $\beta$ subunit of the I- $A^{\mathrm{b}}$ molecule converts the highly susceptible C57BL/ 6 strain of mice into the EAMG-resistant BM12 strain of mice (47). MG patients, like patients with other autoimmune diseases, express some MHC (HLA) alleles with higher frequency than expected in the general population. HLA gene products found frequently in MG patients include the B8 and A1 class I molecule, the DR3/DW3 class II molecule, and certain DQ allele products. Some studies have used mice that express individual DR or DQ alleles transgenically, to determine whether some DR or DQ molecules influence the development of EAMG. Those studies confirmed that expression of the DQ8 and DR3 molecules correlated with EAMG susceptibility and expression of the DQ6 molecule correlated with resistance $(48,49)$.

Role of $\mathrm{CD}^{+}$T cell subtypes and cytokines in MG and EAMG. Differentiated $\mathrm{CD} 4^{+} \mathrm{T}$ cells are classified into subtypes based on the cytokines they secrete. Among them, Th1 and Th2 cells have different and at times opposing functions (50) (Figure 3). Th1 cells secrete proinflammatory cytokines, such as IL- 2 , IFN- $\gamma$, and TNF- $\alpha$, which are important in cell-mediated immune responses. Th2 cells secrete antiinflammatory cytokines, such as IL-4, IL-6, and IL-10, which are also important inducers of humoral immune responses. Moreover, IL-4 stimulates differentiation of Th3 cells, which secrete TGF- $\beta$ and are involved in immunosuppressive mechanisms (51). Both Th1 and Th 2 cytokines may induce Ab synthesis. However, they support the synthesis of different Ig types. In mice (and likely in humans) Th1 cells induce IgG subclasses that bind and activate complement efficiently whereas Th2 cells induce Ig isotypes and IgG subclasses that fix complement poorly or not at all. In rats, both Th1 and Th2 cells induce complement-fixing IgG subclasses (52).
MG patients have abundant anti-AChR Th1 cells in the blood that recognize many AChR epitopes (e.g., see ref. 53) and induce synthesis of pathogenic anti-AChR Abs when grafted together with $B$ cells and macrophages from the same patient into SCID mice (41). MG patients also have anti-AChR Th2 and Th3 cells in the blood (54). Mice congenitally lacking or overexpressing a cytokine have been used to study the role of cytokines in EAMG. Those studies suggested that Th1 cells and their cytokines are needed for EAMG development, probably because they induce expression of complement-binding pathogenic anti-AChR Abs (e.g., see refs. 26, 55). The resistance to EAMG induction conferred by genetic deficiency in TNF- $\alpha$ or TNF receptor proteins (56) is overcome by treatment with IL-12, confirming that sensitization and differentiation of Th1 cells is important for EAMG development (57). Other studies demonstrated the important role of Th1 cells in EAMG by changing the concentration of Th1 cytokines in rodents with normal genes for cytokines and their receptors. For example, treatment of rats with anti-TNF- $\alpha$ Abs suppresses EAMG development (58), and treatment of mice with a soluble recombinant form of the human TNF receptor, able to outcompete mouse TNF- $\alpha$ for binding to the mouse receptor, significantly improves symptoms of established EAMG (59). Moreover, estrogen enhances EAMG development in mice by promoting augmented IL-12 production by AChR-specific Th1 cells, suggesting that estrogens mediate sex differences in autoimmunity because of a Th1-mediated mechanism (60) (Figure 3). Proinflammatory Th1 cytokines induce expression of MHC class II molecules in muscle, thereby facilitating presentation of muscle AChR epitopes and further expansion of activated anti-AChR CD4 ${ }^{+}$ $T$ cells (61). Increased IFN- $\gamma$ production may explain the increased expression of IFN- $\gamma$-induced chemokines and monokines and their receptors in muscle, thymus, and lymph nodes in MG patients and rats with EAMG. A decrease in chemokine expression correlates with decreased severity of symptoms (62).

Anti-AChR Th2 cells have complex and contrasting roles in EAMG. They can be protective (e.g., refs. 63, 64), but the Th2 cytokines IL-5, IL-6, and IL-10 also foster EAMG development (e.g., refs. 65-67). The resistance to EAMG of mice genetically deficient in IL- 6 is associated with a reduced formation of germinal centers in the spleen and a reduced synthesis of anti-AChR IgG Abs while the anti-AChR IgM response is normal, suggesting a defect in $\mathrm{T}$ cell help and in the switching from IgM to IgG isotypes (67).

Other $\mathrm{CD}^{+} \mathrm{T}$ cell subtypes may have a role in $\mathrm{MG}$. $\mathrm{CD}^{+} \mathrm{T}$ cells that express the CD25 marker and the transcription factor Foxp3 are known as Tregs and are important in maintaining self tolerance (Figure 3). Tregs in MG patients may be functionally impaired (68). In addition, the number of circulating Tregs has been shown to increase after thymectomy, and the increase correlated with symptom improvement (69).

Role of NK and NKT cells in MG and EAMG. CD1-d-restricted NKT cells may be involved in maintaining self tolerance. In EAMG and MG, NKT cells and Tregs may cooperate in regulating the antiAChR response. In AChR-immunized mice, activation of NKT cells by a synthetic glycolipid agonist inhibits EAMG development; these therapeutic effects are likely mediated by the increase in number and modulatory function of Tregs induced by the glycolipid (70).

NK cells can also influence the development of EAMG and possibly MG. In mice, NK cells are necessary for EAMG development (71). The "permissive" role of NK cells in EAMG is due to their secreting IFN- $\gamma$, thereby permitting and enhancing the sensitization of Th1 cells. IL-18 is an important growth and differentiation 


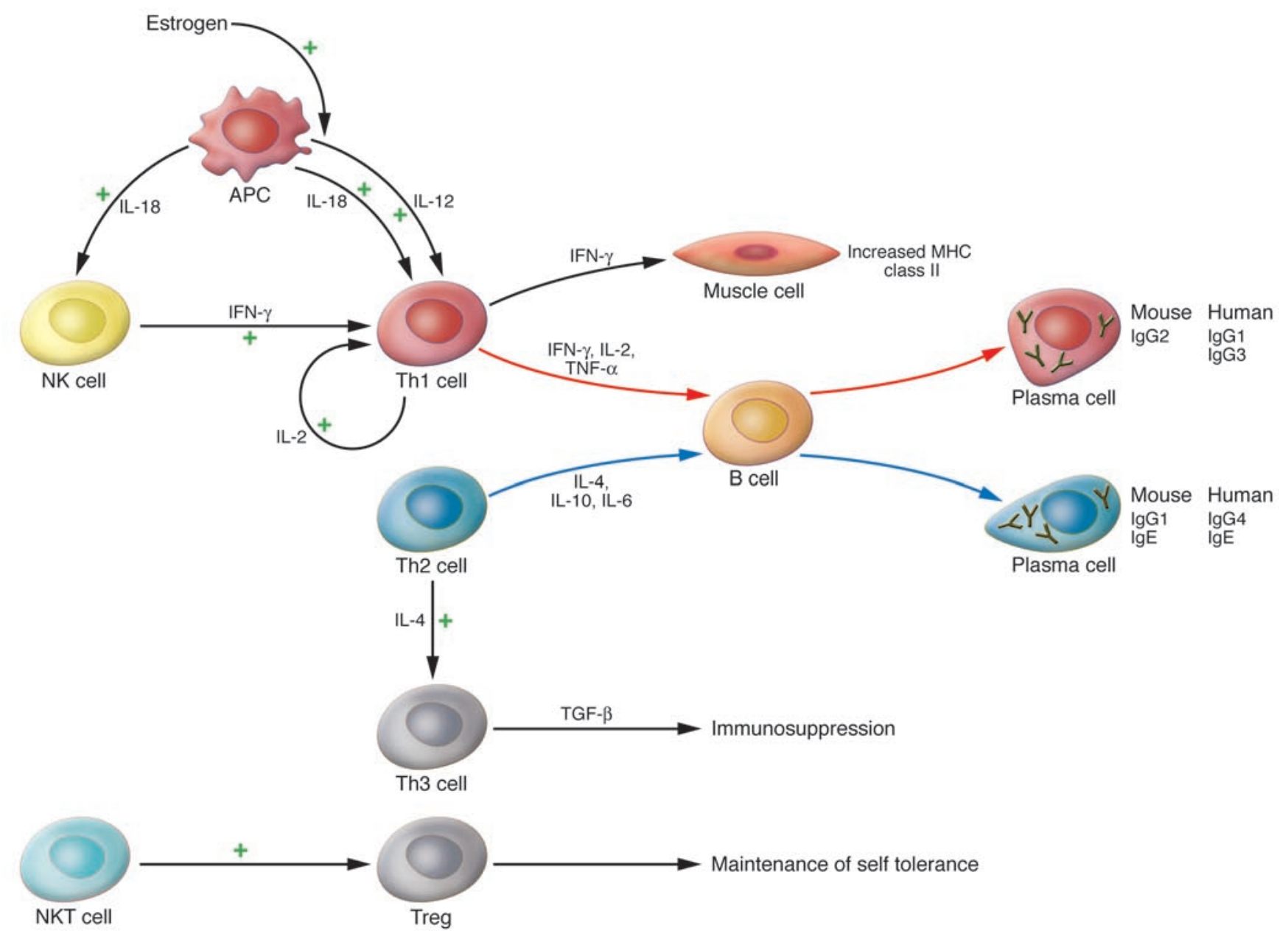

Figure 3

Cytokine network and cells involved in the pathogenesis and immunoregulation of MG. Th1 cytokines stimulate production of IgG subclasses that bind and activate complement effectively, whereas Th2 cytokines stimulate the production of Ig classes and IgG subclasses that do not. The Th2 cytokine IL-4 is also a differentiation factor for Th3 cells, immunosuppressive cells that secrete TGF- $\beta$. The Th1 cytokine IFN- $\gamma$ stimulates expression of MHC class II molecules on the muscle cell membrane, thus facilitating presentation of muscle AChR. The IL-18 secreted by APCs favors the differentiation of Th1 cells both directly and indirectly through the action of NK cells. CD1-d-restricted NKT cells can activate Tregs, thereby inhibiting autoimmune processes. See text for further details.

factor for both NK cells and Th1 cells, especially in cooperation with IL-12 (55). Thus, IL-18 may be especially important in MG and EAMG pathogenesis. This is supported by the finding that IL-18-deficient mice are resistant to EAMG and pharmacologic block of IL-18 suppresses EAMG $(55,71)$. The finding that MG patients have increased serum levels of IL-18, which are higher in $\mathrm{gMG}$ than in oMG patients and tend to decrease with clinical improvement, supports a role for IL-18 in human MG (72).

Other autoantigens in MG. Up to $20 \%$ of MG patients do not have anti-AChR Abs and are consequently known as seronegative patients (73). Many seronegative patients (31\%-41\% in most studies) (74) develop Abs against MuSK. Lower frequencies of patients with anti-MuSK Abs among seronegative MG patients may occur in particular ethnic groups or geographic locations (e.g., Chinese, Norwegians) $(74,75)$; this might reflect environmental or genetic susceptibility factors. MG patients with anti-MuSK Abs never have anti-AChR Abs, with the notable exception of a group of Japanese patients investigated in one study $(74,76)$.
The agrin/MuSK signaling pathway likely maintains the structural and functional integrity of the postsynaptic NMJ apparatus also in adult muscle. Anti-MuSK Abs and IgG from MG patients who have anti-MuSK Abs disrupt AChR aggregation in myotubes from MuSK-immunized animals and block agrin-induced AChR clustering $(12,77)$. Also, immunization of animals with MuSK fragments induces myasthenic symptoms (77). This suggests that anti-MuSK Abs affect the agrin-dependent maintenance of AChR clusters at the NMJ, ultimately leading to reduced AChR numbers. Complement-mediated damage might also be responsible for loss of AChRs and NMJ damage. However, some MG patients with anti-MuSK Abs do not experience AChR loss at the NMJ (78), perhaps because anti-MuSK Abs are mainly IgG4, which do not bind complement efficiently (79). Moreover, some studies have found that anti-MuSK Abs do not cause substantial AChR loss, complement deposition, or morphologic damage at the NMJ (78). AntiMuSK Abs may have other pathogenic mechanisms. In this regard, a recent study that investigated the effects of anti-MuSK Ab-con- 
Table 1

Diagnostic tests for MG

\begin{tabular}{|c|c|c|}
\hline Test & Sensitivity & Comments \\
\hline \multicolumn{3}{|l|}{ Clinical tests } \\
\hline Edrophonium & Detectable in $80 \%-90 \%$ of MG patients & $\begin{array}{l}\text { Edrophonium testing is safe. However, because of known adverse } \\
\text { effects, alternative nonpharmacological tests have been developed. }\end{array}$ \\
\hline Sleep & Criteria poorly defined & \\
\hline Ice-pack test & Criteria poorly defined & \\
\hline \multicolumn{3}{|l|}{ Assays of serum Abs } \\
\hline Anti-AChR & $\begin{array}{l}\text { Detectable in approximately } 80 \%-90 \% \text { of } \\
\text { gMG patients and } 30 \%-50 \% \text { of oMG patients }\end{array}$ & $\begin{array}{l}\text { May also be observed in patients with Lambert-Eaton syndrome and } \\
\text { motor neuron disease, thymoma patients without MG, and relatives } \\
\text { of MG patients. }\end{array}$ \\
\hline Anti-MuSK & $\begin{array}{l}\text { Detectable in approximately } 30 \%-40 \% \text { of } \\
\text { anti-AChR Ab-negative gMG patients and } \\
\text { rarely in oMG patients }\end{array}$ & \\
\hline Anti-striational protein & $\begin{array}{l}\text { Detectable in } 80 \% \text { of thymomatous MG } \\
\text { patients and } 30 \% \text { of nonthymomatous } \\
\text { MG patients }\end{array}$ & $\begin{array}{l}\text { More common in older patients. First autoantibody detected in MG. } \\
\text { However, poor specificity makes this test nondiagnostic. }\end{array}$ \\
\hline \multicolumn{3}{|l|}{ Electrodiagnostic tests } \\
\hline $\begin{array}{l}\text { Repetitive stimulation } \\
\text { of peripheral nerves }\end{array}$ & $\begin{array}{l}\text { Positive in approximately } 90 \% \text { of gMG } \\
\text { patients and } 30 \%-60 \% \text { of oMG patients }\end{array}$ & \\
\hline $\begin{array}{l}\text { Single-fiber } \\
\text { electromyography }\end{array}$ & Positive in $95 \%-99 \%$ of MG patients & $\begin{array}{l}\text { Despite its sensitivity, single-fiber electromyography is not the test of } \\
\text { choice because it is dependent on operator skills and patient } \\
\text { cooperation. Also, results are abnormal in neuropathies and motor } \\
\text { neuron and muscle diseases. }\end{array}$ \\
\hline
\end{tabular}

taining sera from MG patients on muscle cell cultures found that some sera inhibit cell proliferation by causing cell cycle arrest and cause downregulation of the expression of AChR subunits, rapsyn, and other muscle proteins (80).

Some seronegative patients who do not have either anti-AChR or anti-MuSK Abs might have a plasma factor that activates a second messenger pathway in the muscle, resulting in phosphorylation and inactivation of the AChR (81). MG patients may also synthesize Abs against non-muscle-specific proteins, such as myofibrillar proteins (82). Some of those Abs, especially anti-myosin Abs and anti-fast troponin Abs, may cross-react with the AChR (83). MG patients with thymoma have Abs against titin (84) and the ryanodine receptor $(85)$.

\section{Diagnosis of MG}

Textbook descriptions suggest that clinical diagnosis of MG should be straightforward. However, this is not always the case. Delayed or missed diagnoses occur frequently. This is because MG is relatively rare and therefore unfamiliar to practitioners, and its fluctuating muscular weakness can be puzzling. Once suspected, the diagnosis of MG relies on serological tests that detect anti-AChR or anti-MuSK Abs and sometimes Abs against other muscle proteins (actin, striational protein) and electrodiagnostic tests that detect characteristic defects in neuromuscular transmission (Table 1).

The discovery of anti-AChR Abs yielded useful diagnostic tests. The demonstration of serum anti-AChR Abs proves the diagnosis of MG. However, their absence does not exclude it because anti-AChR Abs are detectable only in $80 \%-90 \%$ of gMG patients and $30 \%-50 \%$ of oMG patients (86). The most commonly used anti-AChR Ab assay measures the serum levels of an autoantibody that precipitates muscle AChR extracted from appropriate human cell lines or amputated tissue. The AChR is detected by the binding of a radiolabeled, irreversible cholinergic antagonist, $\alpha$-bungarotoxin (86). Thus, this assay cannot reveal anti-AChR Abs against the cholinergic site, which can be assayed by testing the ability of the patients' IgG to competitively inhibit the binding of cholinergic ligands (86). Yet another serologic test measures the ability of the patients' sera or IgG to induce antigenic modulation of the AChR in cell cultures (86). In patients with MG symptoms who do not have detectable anti-AChR Abs (73), serologic diagnosis of MG can be attempted by determining the presence of anti-MuSK Abs (12). About 5\% of MG patients have neither anti-AChR nor anti-MuSK Abs.

Standard electrodiagnostic tests that utilize repetitive stimulation of peripheral nerves are commonly used to detect neuromuscular transmission defect in MG. They are relatively sensitive and reliable (Table 1). The most sensitive electrodiagnostic test for MG is single-fiber electromyography, which reveals deficits of neuromuscular transmission in $95 \%-99 \%$ of MG patients and excludes the diagnosis of MG when it yields normal results (87). It selectively records action potentials from a small number (usually 2 or 3 ) of muscle fibers innervated by a single motor unit. The amount of ACh released at the NMJ at different times has a small variability, resulting in comparable variations in the rise of EPP and the muscle fiber pair interpotential intervals. This variability is highly sensitive to neuromuscular transmission abnormalities and is increased in MG patients. Neuromuscular blocking is the failure of transmission of one of the potentials, when one of the muscle fibers fails to transmit an action potential because the EPP does not reach the necessary threshold. The American Association of Neuromuscular $\&$ Electrodiagnostic Medicine has developed guidelines for electrodiagnostic testing for evaluation of MG (88). 


\section{Table 2}

Current and potential therapies for MG management

\begin{tabular}{|c|c|c|}
\hline Approach & Therapeutics & Mechanism of action \\
\hline \multicolumn{3}{|l|}{ Current } \\
\hline $\begin{array}{l}\text { Modulation of neuromuscular } \\
\text { transmission }\end{array}$ & $\begin{array}{l}\text { Cholinesterase inhibitors } \\
\text { EN101 }\end{array}$ & $\begin{array}{l}\text { Prolong ACh activity } \\
\text { Antisense nucleotide that suppresses the synthesis of AChE-R, the soluble } \\
\text { and most effective form of synaptic AChE }\end{array}$ \\
\hline Immunomodulation & $\begin{array}{l}\text { Thymectomy } \\
\text { Plasma exchange } \\
\text { IVIg } \\
\text { Immunoadsorption }\end{array}$ & $\begin{array}{l}\text { Probably multiple effects } \\
\text { Removal of Ab } \\
\text { Multiple effects } \\
\text { Removal of anti-AChR Ab }\end{array}$ \\
\hline General immunosuppression & $\begin{array}{l}\text { Prednisone } \\
\text { Azathioprine } \\
\text { Cyclosporine, Tacrolimus } \\
\text { Mycophenolate mofetil } \\
\text { Etanercept }\end{array}$ & $\begin{array}{l}\text { Multiple effects } \\
\text { Purine analog. Inhibits T and B cell proliferation } \\
\text { Blocks T cell activation and growth } \\
\text { Inhibits guanosine nucleotide synthesis and selectively inhibits activated T cells } \\
\text { Recombinant soluble TNF receptor that competitively inhibits TNF- } \alpha \text { binding }\end{array}$ \\
\hline \multicolumn{3}{|l|}{ Potential } \\
\hline Complement inhibition & $\begin{array}{l}\text { Anti-C6 Abs } \\
\text { CR1 }\end{array}$ & $\begin{array}{l}\text { Abs that block complement component } 6 \text { and protect rodents from EAMG } \\
\text { Soluble recombinant receptor that competitively inhibits complement }\end{array}$ \\
\hline Induction of tolerance to AChR & Multiple approaches & $\begin{array}{l}\text { Administration of AChR or portion of sequence by tolerance-inducing routes } \\
\text { (e.g., oral, nasal) } \\
\text { T cell vaccination } \\
\text { Use of modified APCs loaded with AChR epitopes }\end{array}$ \\
\hline $\begin{array}{l}\text { Depletion of AChR-specific B } \\
\text { or T cells }\end{array}$ & Multiple approaches & $\begin{array}{l}\text { For example, AChR toxin to eliminated B cells, Fas ligand conjugates targeted } \\
\text { to T cells }\end{array}$ \\
\hline $\begin{array}{l}\text { Interruption of MHC class II, } \\
\text { epitope peptide, T cell receptor, } \\
\text { and CD4+ complex }\end{array}$ & Multiple approaches & For example, APL (peptide epitope analogs that cannot activate CD4+ $T$ cells) \\
\hline
\end{tabular}

\section{Therapeutic MG management}

The current management of MG includes the use of anticholinesterase drugs for temporary improvement of neuromuscular transmission, removal of anti-AChR Abs by plasma exchange or specific immunoadsorption procedures, use of nonspecific immunosuppressants or immunomodulators to curb the anti-AChR response, and thymectomy (Table 2). No current treatment targets the autoimmune defect of MG selectively. However, the advances in understanding the pathogenesis of autoimmunity and MG suggest that new approaches that will curb or even eliminate the anti-AChR response specifically will be forthcoming (see Table 2 and "The future").

Anticholinesterase drugs improve myasthenic symptoms in nearly all patients, but they fully relieve the symptoms in only a few. Thus, most patients require additional immunosuppressive treatment (see below). A novel approach to long-term therapeutic inhibition of AChE activity in MG patients is based on the observation that in the NMJ of both MG patients and EAMG animals, there is enhanced transcription and altered splicing of AChE pre-mRNA, with accumulation of a normally rare readthrough AChE-R variant (89). The commonly occurring synaptic AChE-S variant forms membrane multimers. In contrast, AChE-R exists as soluble monomers that lack the carboxyterminal cysteine needed for membrane attachment. Thus, AChE-R permeates the synaptic space and degrades ACh before it reaches the postsynaptic membrane, thereby compromising AChR activation. These observations prompted the design and use of EN101, an antisense oligonucleotide that suppresses the expression of AChE-R. EN101 normalizes neuromuscular transmission in EAMG by modulat- ing the synthesis of AChE variants, thereby affecting the rate of ACh hydrolysis and the efficacy of AChR activation (90). EN101 is undergoing human trials.

Despite the lack of large controlled trials, corticosteroids are the immunosuppressive agent most frequently used for the treatment of MG and the most consistently effective (91). They are administered at high doses for several months and at low doses for years. Anti-AChR Ab levels decrease in the first months of therapy. Most patients obtain a clinical benefit, which may be related to reduction of lymphocyte differentiation and proliferation, redistribution of lymphocytes into tissues that are not sites of immunoreactivity, changes in cytokine expression (primarily of TNF, IL-1, and IL-2), inhibition of macrophage function and of antigen processing and presentation, or a possible increase in muscle AChR synthesis. The shortcoming of corticosteroid treatment is the frequent steroid-related complications. This has motivated the use of other immunosuppressants, either as "steroid-sparing" agents or as a substitute for corticosteroids; a proportion of MG patients can be treated successfully without corticosteroids.

Azathioprine, a purine analog, reduces nucleic acid synthesis, thereby interfering with $\mathrm{T}$ and $\mathrm{B}$ cell proliferation. It has been utilized as a single immunosuppressant agent in MG since the 1970s, and large, retrospective reports support its efficacy (92). A randomized, double-blind trial demonstrated its efficacy also as a steroid-sparing agent. Its major disadvantage is the delayed clinical response, which may take up to 15 months (93).

Cyclophosphamide administered intravenously and orally is an effective treatment for MG (94); more than half of the 
patients became asymptomatic after 1 year of treatment. Its delayed effect and undesirable side effects (hair loss, and less frequently, nausea, vomiting, anorexia, and skin discoloration) limits its use to the management of patients who do not respond to other immunosuppressive treatments.

Cyclosporine is a cyclic undecapeptide that blocks the synthesis of cytokines (and especially IL-2), IL-2 receptors, and other proteins critical in the function of $\mathrm{CD}^{+}{ }^{+} \mathrm{T}$ cells. Its efficacy in $\mathrm{MG}$ was first suggested by a small, randomized, placebo-controlled study, which has not been followed by similar studies on larger groups of patients (95). However, larger retrospective studies have supported its use as a steroid-sparing agent (96).

Tacrolimus, a macrolide antibiotic, is similar to cyclosporine in its biological activity. No large controlled studies on the efficacy of tacrolimus in MG are available. However, a large retrospective study of treatment-resistant patients supports its use as a steroid-sparing agent (97).

In the US, mycophenolate mofetil is increasingly used both as a steroid-sparing agent and as a stand-alone immunosuppressant. Unfortunately, the investigations that support its use studied small patient groups or were of a retrospective nature; therefore the value of their conclusions is limited (98). Those studies suggest that mycophenolate has limited toxicity, consistent with its selective inhibitory activity of guanosine nucleotide synthesis in activated T and B cells, which should limit its effects on other cell types (99). Randomized, controlled trials to evaluate mycophenolate mofetil usefulness in MG treatment are under way.

For some MG patients, symptoms do not improve with the use of corticosteroids or one of the immunosuppressive agents described above, alone or in combination, and they may develop intolerable side effects prompting consideration of other therapeutic options. MG patients resistant to therapy have been successfully treated with cyclophosphamide in combination with bone marrow transplant (100) or with rituximab, a monoclonal Ab against the B cell surface marker CD20 (101). Etanercept, a soluble, recombinant TNF receptor that competitively blocks the action of TNF- $\alpha$, has been shown to have a steroid-sparing effects in studies on small groups of patients (102). Plasma exchange and i.v. Ig (IVIg) (discussed below) can be used as chronic therapy although their benefit has not been documented in rigorously designed studies.

Plasma exchange (plasmapheresis) and IVIg are used for acute management of severe muscular weakness. Plasmapheresis involves replacing 1-1.5 times the plasma volume with saline, albumin, or plasma protein fraction, leading to a reduction of serum AChR Ab levels (103). For IVIg therapy, Ig isolated from pooled human plasma by ethanol cryoprecipitation is administered for 5 days $(0.4 \mathrm{~g} / \mathrm{kg} /$ day $)$. Fewer infusions at higher doses are also used. The mechanism of action of IVIg is complex and likely includes inhibition of cytokines, competition with autoantibodies, inhibition of complement deposition, interference with binding of Fc receptor on macrophages and Ig receptor on B cells, and interference with antigen recognition by sensitized T cells (104). More specific techniques to remove pathogenic anti-AChR Abs utilizing immunoadsorption have been developed recently, which offer a more targeted approach to MG treatment (105).

The observations that lead to therapeutic ablation of the thymus in MG have been mentioned above. However, the clinical efficacy of thymectomy has been questioned because the evidence supporting its use is not solid (106). Retrospective studies yielded widely different conclusions, but they included patients whose thymi were removed by different surgical approaches, and they used different definitions of remission and limited statistical analysis (107). Moreover, corticosteroids and other immunosuppressive agents are commonly used by MG patients undergoing thymectomy, making it difficult to ascertain whether thymectomy provides additional benefits. Usually, thymectomy is performed on patients early in the course of their disease and restricted to patients younger than 60. A review by the American Academy of Neurology concluded that, while thymectomy should be considered a treatment option, its benefits in nonthymomatous MG have not been firmly established (106) and that a prospective, controlled, randomized study with standardized medical therapy for all patients is needed. Also, the NIH is sponsoring a clinical trial to determine whether the extended transsternal thymectomy reduces corticosteroid requirements for patients with AChR Ab-positive nonthymomatous gMG (108).

Thymectomy may not be a viable therapeutic approach for antiMuSK Ab-positive patients because their thymi lack the germinal centers and the infiltrates of lymphocytes that characterize thymi from patients who have anti-AChR Abs. This suggests that a different pathologic mechanism occurs in anti-MuSK Ab-positive and anti-AChR Ab-positive MG.

Lack of well-designed investigations with appropriate statistical power undermines the rationale for use of the current immunotherapies for MG. Moreover, there are no rigorous trials that compare the efficacy of the various immunosuppressive approaches. Different factors contribute to this situation, including the variable clinical presentations and time course of MG and its low incidence; a lack of agreed-upon clinical scales to measure the outcome of the treatment; and a suboptimal cooperation among the major centers that care for MG patients during clinical trials (109).

\section{The future}

Complement inhibition is an attractive future therapeutic approach for MG because it is effective in rodent EAMG (e.g., ref. 24). Moreover, anti-C5 inhibitors show short-term safety and are effective in a variety of human disorders, including myocardial infarction (110), coronary artery bypass graft surgery (111), and lung transplantation (112). Thus, therapeutic approaches based on inhibition of complement activation will likely be tried for MG in the future.

However, the ultimate goal for MG treatment is to eradicate the rogue anti-AChR autoimmune response specifically and reestablish tolerance to the AChR without affecting the other functions of the immune system or causing other adverse effects. Such targeted immunosuppressive approaches (Table 2) are still far from clinical use. However, their success in EAMG suggests that approaches for specific modulation of the autoimmune anti-AChR response may become part of MG patient care in the next decade. We will summarize here the different approaches that have proven successful for the prevention and treatment of EAMG induced by immunization with AChR. We will also analyze the possible technical and biological limitations to their application for the treatment of human MG.

Approaches that have proven successful in rodent EAMG include the following: (a) administration of AChR or parts of its sequence in a manner known to induce tolerance; (b) depletion of AChRspecific B cells or T cells; and (c) interference with formation of the complex between MHC class II molecules, epitope peptide, T cell receptor, and CD4 molecule.

Antigen presentation under special circumstances may lead to antigen-specific tolerance in adult animals rather than activated $\mathrm{CD}^{+} \mathrm{T}$ cells. Earlier studies showed that in rats, presentation of 
AChR epitopes by unsuitable APCs (fixed B cells that had been incubated with AChR under conditions favoring AChR uptake and processing) caused unresponsiveness of the AChR-specific $\mathrm{CD}^{+}$ $\mathrm{T}$ cells to further stimulation with AChR (113). More recently, several studies have demonstrated that DCs, especially after treatment with TGF- $\beta$, IFN- $\gamma$, or IL-10, when injected into rats with developing or ongoing EAMG, suppressed or ameliorated the myasthenic symptoms (114-116). The effect was correlated with a reduced production of anti-AChR Abs without a reduced proliferative response of $\mathrm{T}$ cells to the AChR. Approaches based on the use of tolerance-inducing APCs, which should present all AChR epitopes and therefore influence all AChR-specific T cells, might be useful for the treatment of MG. Should pulsing of the APCs with human AChR be needed, biosynthetic human AChR subunits could be used as antigens.

Mucosal or subcutaneous administration of AChR or synthetic or biosynthetic AChR peptides to rodents - approaches known to induce antigen-specific tolerance in adult animals - prevented or delayed EAMG development (e.g., see refs. 117-119). Depending on the dose of the antigen administered, anergy/deletion of antigen-specific T cells (at high doses) and/or expansion of cells producing immunosuppressive cytokines (TGF- $\beta$, IL-4, IL-10) (at low doses) are major mechanisms in mucosal tolerance induction. The use of mucosal tolerization procedures in human MG, however, is problematic because those procedures can be a double-edged sword (120); they reduce AChR-specific $\mathrm{CD}^{+} \mathrm{T}$ cell responses but may also stimulate AChR-specific B cells to produce Abs, thereby worsening the disease. Also, a large amount of human AChRs would be required, which may be difficult to obtain.

Conjugates of a toxin with AChR or synthetic AChR sequences, when administered to animals with EAMG, eliminated B cells producing anti-AChR Abs (121). This is probably because the AChR moiety of the conjugate docks onto the membrane-bound Abs of AChR-specific B cells, which can then be killed by the toxic domain. This approach has 2 caveats. First, the toxin may damage other cells. Second, anti-AChR CD4 ${ }^{+} \mathrm{T}$ cells can recruit new B cells to synthesize more anti-AChR Abs.

AChR-specific $\mathrm{CD}^{+} \mathrm{T}$ cells can be specifically eliminated in vitro by APCs genetically engineered to express relevant portions of the AChR, Fas ligand (to eliminate the activated AChR-specific $T$ cells with which they interact), and a portion of Fas-associated death domain, which prevents self-destruction by the Fas ligand (122). It is not known yet whether this strategy can be safely used to modulate EAMG in vivo.

Activation of $\mathrm{CD}^{+} \mathrm{T}$ cells requires interaction and stable binding of several proteins on the surfaces of the $\mathrm{CD}^{+} \mathrm{T}$ cell and of the APC. In experimental systems, interfering with formation of this complex usually reduced the activity of autoimmune $\mathrm{CD} 4^{+} \mathrm{T}$ cells. This may be obtained by administering or inducing Abs that recognize the binding site for the antigen of the $\mathrm{T}$ cell receptor (known as T cell vaccination) (123). T cell vaccination is already used in clinical trials for the treatment of multiple sclerosis, rheumatoid arthritis, and psoriasis (124). It is effective in EAMG, and it is a promising future strategy for the treatment of MG (124). The mechanisms of action of $T$ cell vaccination are complex, and they likely include the induction of modulatory $\mathrm{CD}^{+}$and $\mathrm{CD}^{+} \mathrm{T}$ cells (124). Another approach used synthetic peptide analogs of an epitope recognized by autoimmune $\mathrm{CD}^{+} \mathrm{T}$ cells that bind the MHC class II molecules but cannot stimulate the specific $\mathrm{CD}^{+}$cells. These are known as altered peptide ligands (APLs). APLs compete with peptide epitopes derived from the autoantigen, thereby turning off the autoimmune response. APLs might also stimulate modulatory antiinflammatory $\mathrm{CD}^{+} \mathrm{T}$ cells or anergize the pathogenic $\mathrm{CD}^{+} \mathrm{T}$ cells (125). The rich epitope repertoire of anti-AChR $\mathrm{CD}^{+} \mathrm{T}$ cells in MG patients reduces the therapeutic potential of approaches that interfere with activation of specific $\mathrm{CD}^{+} \mathrm{T}$ cells; targeting only a few epitopes may not significantly reduce the anti$\mathrm{AChR}$ response. Moreover, these treatments are likely to produce only transient improvement that ceases when administration of the anti-T cell $\mathrm{Ab}$ is discontinued.

MG and EAMG have offered unique opportunities to investigate the molecular mechanisms of an Ab-mediated autoimmune disease. Many factors have contributed to making MG the best understood human autoimmune disease. These include the simplicity of the pathogenic mechanism in MG, where NMJ failure explains all symptoms; the deeper understanding of the structure and the function of the NMJ and its molecular components, most notably, the AChR; and the increasing understanding of the mechanisms that modulate immune responses and maintain tolerance. Hopefully increasing knowledge of the immunobiology of MG will form a foundation for designing new and specific therapeutic approaches aimed at curbing the rogue autoimmune response and reestablishing immunological tolerance without interfering with the other immune functions.

If this expectation is fulfilled, MG, which has been a benchmark to understanding autoimmunity in humans, will become a reference point for the design of specific immunosuppressive treatments of other autoimmune Ab-mediated diseases.

\section{Acknowledgments}

The authors are supported by grants from the NIH (NS23919 to B.M. Conti-Fine; EY013238 and R24EY014837 to H.J. Kaminski) and from the Muscular Dystrophy Association of America (to M. Milani and B.M. Conti-Fine).

Address correspondence to: Bianca M. Conti-Fine, Department of Biochemistry, Molecular Biology, and Biophysics, University of Minnesota, 6-155 Jackson Hall, 321 Church St. SE, Minneapolis, Minnesota 55455, USA. Phone: (612) 624-6796; Fax: (612) 6252163; E-mail: conti001@umn.edu.
1. Robertson, D.N. 2000. Enumerating neurology. Brain. 123:663-664.

2. Marsteller, H.B. 1988. The first American case of myasthenia gravis. Arch. Neurol. 45:185-187.

3. Pascuzzi, R.M. 1994. The history of myasthenia gravis. Neurol. Clin. 12:231-242.

4. Keesey, J.C. 2002. "Crisis" in myasthenia gravis: an historical perspective. Muscle Nerve. 26:1-3.

5. Walker, M.B. 1935. Case showing the effect of prostigmin on myasthenia gravis. Proc. R. Soc. Med. 28:759-761.

6. Nastuk, W.L., Strauss, A.J., and Osserman, K.E.
1959. Search for a neuromuscular blocking agent in the blood of patients with myasthenia gravis. Am. J. Med. 26:394-409.

7. Simpson, J.A. 1960. Myasthenia gravis, a new hypothesis. Scott. Med. J. 5:419-436.

8. Patrick, J., and Lindstrom, J. 1973. Autoimmune response to acetylcholine receptor. Science. 180:871-872.

9. Rowland, L.P. 1980. Controversies about the treatment of myasthenia gravis. J. Neurol. Neurosurg. Psychiatr. 43:644-659.

10. Lehmann, H.C., Hartung, H.P., Hetzel, G.R., Stuve,
O., and Kieseier, B.C. 2006. Plasma exchange in neuroimmunological disorders: part 2. Treatment of neuromuscular disorders. Arch. Neurol. 63:1066-1071.

11. Horton, R.M., Manfredi, A.A., and Conti-Tronconi, B. 1993. The 'embryonic' gamma subunit of the nicotinic acetylcholine receptor is expressed in adult extraocular muscle. Neurology. 43:983-986.

12. Hoch, W., et al. 2001. Auto-antibodies to the receptor tyrosine kinase MuSK in patients with myasthenia gravis without acetylcholine receptor antibodies. Nat. Med. 7:365-368. 
13. Ruegg, M.A., and Bixby, J.L. 1998. Agrin orchestrates synaptic differentiation at the vertebrate neuromuscular junction. Trends Neurosci. 21:22-27.

14. Glass, D.J., et al. 1996. The receptor tyrosine kinase MuSK is required for neuromuscular junction formation and is a functional receptor for agrin. Cold Spring Harb. Symp. Quant. Biol. 61:435-444.

15. Hughes, B.W., Kusner, L.L., and Kaminski, H.J. 2006. Molecular architecture of the neuromuscular junction. Muscle Nerve. 33:445-461.

16. Khanna, S., and Porter, J.D. 2002. Conservation of synapse-signaling pathways at the extraocular muscle neuromuscular junction. Ann. N. Y. Acad. Sci. 956:394-396.

17. Kaminski, H.J., Li, Z., Richmonds, C., Lin, F., and Medof, M.E. 2004. Complement regulators in extraocular muscle and experimental autoimmune myasthenia gravis. Exp. Neurol. 189:333-342.

18. Wood, S.J., and Slater, C.R. 1997. The contribution of postsynaptic folds to the safety factor for neuromuscular transmission in rat fast- and slow-twitch muscles. J. Physiol. 500:165-176.

19. Sterz, R., Pagala, M., and Peper, K. 1983. Postjunctional characteristics of the endplates in mammalian fast and slow muscles. Pflugers Arch. 398:48-54.

20. Ruff, R.L. 1996. Single-channel basis of slow inactivation of $\mathrm{Na}^{+}$channels in rat skeletal muscle. Am.J. Physiol. 271:C971-C981.

21. Sahashi, K., Engel, A.G., Lambert, E.H., and Howard, F.M., Jr. 1980. Ultrastructural localization of the terminal and lytic ninth complement component (C9) at the motor end-plate in myasthenia gravis. J. Neuropathol. Exp. Neurol. 39:160-172.

22. Lennon, V.A., Seybold, M.E., Lindstrom, J.M., Cochrane, C., and Ulevitch, R. 1978. Role of complement in the pathogenesis of experimental autoimmune myasthenia gravis. J. Exp. Med. 147:973-983.

23. Biesecker, G., and Gomez, C.M. 1989. Inhibition of acute passive transfer experimental autoimmune myasthenia gravis with Fab antibody to complement C6. J. Immunol. 142:2654-2659.

24. Piddlesden, S.J., Jiang, S., Levin, J.L., Vincent, A., and Morgan, B.P. 1996. Soluble complement receptor 1 (sCR1) protects against experimental autoimmune myasthenia gravis. J. Neuroimmunol. 71:173-177.

25. Christadoss, P. 1988. C5 gene influences the development of murine myasthenia gravis. J. Immunol. 140:2589-2592.

26. Karachunski, P.I., Ostlie, N.S., Monfardini, C., and Conti-Fine, B.M. 2000. Absence of IFN-gamma or IL-12 has different effects on experimental myasthenia gravis in C57BL/6 mice. J. Immunol. 164:5236-5244.

27. Medof, M.E., Walter, E.I., Rutgers, J.L., Knowles, D.M., and Nussenzweig, V. 1987. Identification of the complement decay-accelerating factor (DAF) on epithelium and glandular cells and in body fluids. J. Exp. Med. 165:848-864.

28. McNearney, T., Ballard, L., Seya, T., and Atkinson, J.P. 1989. Membrane cofactor protein of complement is present on human fibroblast, epithelial, and endothelial cells. J. Clin. Invest. 84:538-545.

29. Meri, S., Waldmann, H., and Lachmann, P.J. 1991. Distribution of protectin (CD59), a complement membrane attack inhibitor, in normal human tissues. Lab. Invest. 65:532-537.

30. Lin, F., et al. 2002. Markedly enhanced susceptibility to experimental autoimmune myasthenia gravis in the absence of decay-accelerating factor protection. J. Clin. Invest. 110:1269-1274. doi:10.1172/ JCI200216086

31. Drachman, D.B., Angus, C.W., Adams, R.N., Michelson, J.D., and Hoffman, G.J. 1978. Myasthenic antibodies cross-link acetylcholine receptors to accelerate degradation. N. Engl. J. Med. 298:1116-1122.

32. Engel, A.G., and Fumagalli, G. 1982. Mechanisms of acetylcholine receptor loss from the neuromus- cular junction. Ciba Found. Symp. 90:197-224.

33. Conti-Tronconi, B., Tzartos, S., and Lindstrom, J. 1981. Monoclonal antibodies as probes of acetylcholine receptor structure. 2 . Binding to native receptor. Biochemistry. 20:2181-2191.

34. Gomez, C.M., and Richman, D.P. 1983. Anti-acetylcholine receptor antibodies directed against the alpha-bungarotoxin binding site induce a unique form of experimental myasthenia. Proc. Natl. Acad. Sci.U.S. A. 80:4089-4093.

35. Whiting, P.J., Vincent, A., and Newsom-Davis, J. 1983. Acetylcholine receptor antibody characteristics in myasthenia gravis. Fractionation of alphabungarotoxin binding site antibodies and their relationship to IgG subclass. J. Neuroimmunol. 5:1-9.

36. Eng, H., Lefvert, A.K., Mellstedt, H., and Osterborg, A. 1987. Human monoclonal immunoglobulins that bind the human acetylcholine receptor. Eur. J. Immunol. 17:1867-1869.

37. Hohlfeld, R., Toyka, K.V., Heininger, K., GrosseWilde, H., and Kalies, I. 1984. Autoimmune human $\mathrm{T}$ lymphocytes specific for acetylcholine receptor. Nature. 310:244-246.

38. Morgutti, M., Conti-Tronconi, B.M., Sghirlanzoni, A., and Clementi, F. 1979. Cellular immune response to acetylcholine receptor in myasthenia gravis: II. Thymectomy and corticosteroids. Neurology. 29:734-738.

39. Ahlberg, R., et al. 1994. Treatment of myasthenia gravis with anti-CD4 antibody: improvement correlates to decreased T-cell autoreactivity. Neurology. 44:1732-1737.

40. Nath, A., Kerman, R.H., Novak, I.S., and Wolinsky, J.S. 1990. Immune studies in human immunodeficiency virus infection with myasthenia gravis: a case report. Neurology. 40:581-583.

41. Wang, Z.Y. 1999. Myasthenia in SCID mice grafted with myasthenic patient lymphocytes: role of CD4+ and CD8+ cells. Neurology. 52:484-497.

42. Kaul, R., Shenoy, M., Goluszko, E., and Christadoss, P. 1994. Major histocompatibility complex class II gene disruption prevents experimental autoimmune myasthenia gravis. J. Immunol. 152:3152-3157.

43. Wang, Z.Y., Okita, D.K., Howard, J., Jr., and ContiFine, B.M. 1998. T-cell recognition of muscle acetylcholine receptor subunits in generalized and ocular myasthenia gravis. Neurology. 50:1045-1054.

44. Wang, Z.Y., et al. 2000. T cell recognition of muscle acetylcholine receptor in ocular myasthenia gravis. J. Neuroimmunol. 108:29-39.

45. Protti, M.P., Manfredi, A.A., Straub, C., Howard, J.F., Jr., and Conti-Tronconi, B.M. 1990. Immunodominant regions for $\mathrm{T}$ helper-cell sensitization on the human nicotinic receptor alpha subunit in myasthenia gravis. Proc. Natl. Acad. Sci. U. S. A. 87:7792-7796.

46. Kaul, R., Shenoy, M., and Christadoss, P. 1994. The role of major histocompatibility complex genes in myasthenia gravis and experimental autoimmune myasthenia gravis pathogenesis. Adv. Neuroimmunol. 4:387-402.

47. Christadoss, P., Lindstrom, J.M., Melvold, R.W., and Talal, N. 1985. Mutation at I-A beta chain prevents experimental autoimmune myasthenia gravis. Immunogenetics. 21:33-38.

48. Poussin, M.A., Goluszko, E., David, C.S., Franco, J.U., and Christadoss, P. 2001. HLA-DQ6 transgenic mice resistance to experimental autoimmune myasthenia gravis is linked to reduced acetylcholine receptor-specific IFN-gamma, IL-2 and IL-10 production. J. Autoimmun. 17:175-180.

49. Yang, H., et al. 2003. Induction of myasthenia gravis in HLA transgenic mice by immunization with human acetylcholine receptors. Ann. N. Y. Acad. Sci. 998:375-378.

50. Yates, A., Bergmann, C., Van Hemmen, J.L., Stark, J., and Callard, R. 2000. Cytokine-modulated regu- lation of helper T cell populations. J. Theor. Biol. 206:539-560.

51. Weiner, H.L. 2001. Induction and mechanism of action of transforming growth factor-beta-secreting Th3 regulatory cells. Immunol. Rev. 182:207-214.

52. Saoudi, A., et al. 1999. Experimental autoimmune myasthenia gravis may occur in the context of a polarized Th1- or Th2-type immune response in rats. J. Immunol. 162:7189-7197.

53. Moiola, L., Karachunski, P., Protti, M.P., Howard, J.F., Jr., and Conti-Tronconi, B.M. 1994. Epitopes on the $\beta$ subunit of human muscle acetylcholine receptor recognized by CD4+ cells of myasthenia gravis patients and healthy subjects. J. Clin. Invest. 93:1020-1028.

54. Yi, Q., Ahlberg, R., Pirskanen, R., and Lefvert, A.K. 1994. Acetylcholine receptor-reactive $T$ cells in myasthenia gravis: evidence for the involvement of different subpopulations of T helper cells. J. Neuroimmunol. 50:177-186.

55. Im, S.H., et al. 2001. Suppression of experimental myasthenia gravis, a B cell-mediated autoimmune disease, by blockade of IL-18. FASEB J. 15:2140-2148.

56. Goluszko, E., Deng, C., Poussin, M.A., and Christadoss, P. 2002. Tumor necrosis factor receptor p55 and $\mathrm{p} 75$ deficiency protects mice from developing experimental autoimmune myasthenia gravis. J. Neuroimmunol. 122:85-93.

57. Wang, H.B., et al. 2000. Tumor necrosis factor receptor- 1 is critically involved in the development of experimental autoimmune myasthenia gravis. Int. Immunol. 12:1381-1388.

58. Duan, R.S., et al. 2002. Anti-TNF-alpha antibodies suppress the development of experimental autoimmune myasthenia gravis. J. Autoimmun. 19:169-174.

59. Christadoss, P., and Goluszko, E. 2002. Treatment of experimental autoimmune myasthenia gravis with recombinant human tumor necrosis factor receptor Fc protein. J. Neuroimmunol. 122:186-190.

60. Delpy, L., et al. 2005. Estrogen enhances susceptibility to experimental autoimmune myasthenia gravis by promoting type 1-polarized immune responses. J. Immunol. 175:5050-5057.

61. Hohlfeld, R., and Engel, A.G. 1990. Induction of HLA-DR expression on human myoblasts with interferon-gamma. Am. J. Pathol. 136:503-508.

62. Feferman, T., et al. 2005. Overexpression of IFNinduced protein 10 and its receptor CXCR3 in myasthenia gravis. J. Immunol. 174:5324-5331.

63. Ostlie, N., Milani, M., Wang, W., Okita, D., and Conti-Fine, B.M. 2003. Absence of IL-4 facilitates the development of chronic autoimmune myasthenia gravis in C57BL/6 mice. J. Immunol. 170:604-612.

64. Balasa, B., Deng, C., Lee, J., Christadoss, P., and Sarvetnick, N. 1998. The Th2 cytokine IL-4 is not required for the progression of antibody-dependent autoimmune myasthenia gravis. J. Immunol. 161:2856-2862.

65. Poussin, M.A., Goluszko, E., Hughes, T.K., Duchicella, S.I., and Christadoss, P. 2000. Suppression of experimental autoimmune myasthenia gravis in IL-10 gene-disrupted mice is associated with reduced $B$ cells and serum cytotoxicity on mouse cell line expressing AChR. J. Neuroimmunol. 111:152-160.

66. Poussin, M.A., Goluszko, E., Franco, J.U., and Christadoss, P. 2002. Role of IL-5 during primary and secondary immune response to acetylcholine receptor. J. Neuroimmunol. 125:51-58.

67. Deng, C., Goluszko, E., Tuzun, E., Yang, H., and Christadoss, P. 2002. Resistance to experimental autoimmune myasthenia gravis in IL-6-deficient mice is associated with reduced germinal center formation and C3 production. J. Immunol. 169:1077-1083.

68. Balandina, A., Lecart, S., Dartevelle, P., Saoudi, A., and Berrih-Aknin, S. 2005. Functional defect of regulatory $\mathrm{CD} 4(+) \mathrm{CD} 25+\mathrm{T}$ cells in the thymus of patients with autoimmune myasthenia gravis. 
Blood. 105:735-741.

69. Sun, Y., et al. 2004. Increase of circulating $\mathrm{CD} 4+\mathrm{CD} 25+\mathrm{T}$ cells in myasthenia gravis patients with stability and thymectomy. Clin. Immunol. 112:284-289.

70. Liu, R., et al. 2005. Cooperation of invariant NKT cells and CD4+CD25+ T regulatory cells in the prevention of autoimmune myasthenia. J. Immunol. 175:7898-7904.

71. Shi, F.D., et al. 2000. Natural killer cells determine the outcome of B cell-mediated autoimmunity. Nat. Immunol. 1:245-251.

72. Jander, S., and Stoll, G. 2002. Increased serum levels of the interferon-gamma-inducing cytokine interleukin-18 in myasthenia gravis. Neurology. 59:287-289.

73. Vincent, A., McConville, J., Farrugia, M.E., and Newsom-Davis, J. 2004. Seronegative myasthenia gravis. Semin. Neurol. 24:125-133.

74. Vincent, A., and Leite, M.I. 2005. Neuromuscular junction autoimmune disease: muscle specific kinase antibodies and treatments for myasthenia gravis. Curr. Opin. Neurol. 18:519-525.

75. Yeh, J.H., Chen, W.H., Chiu, H.C., and Vincent, A 2004. Low frequency of MuSK antibody in generalized seronegative myasthenia gravis among Chinese. Neurology. 62:2131-2132.

76. Ohta, K., et al. 2004. MuSK antibodies in AChR Ab-seropositive MG vs AChR Ab-seronegative MG. Neurology. 62:2132-2133.

77. Shigemoto, K., et al. 2006. Induction of myasthenia gravis by immunization against muscle-specific kinase. J. Clin. Invest. 116:1016-1024. doi:10.1172/ JCI21545.

78. Shiraishi, H., et al. 2005. Acetylcholine receptors loss and postsynaptic damage in MuSK antibody-positive myasthenia gravis. Ann. Neurol. 57:289-293.

79. McConville, J., et al. 2004. Detection and characterization of MuSK antibodies in seronegative myasthenia gravis. Ann. Neurol. 55:580-584.

80. Boneva, N., Frenkian-Cuvelier, M., Bidault, J., Brenner, T., and Berrih-Aknin, S. 2006. Major pathogenic effects of anti-MuSK antibodies in myasthenia gravis. J. Neuroimmunol. 177:119-131.

81. Plested, C.P., et al. 2002. AChR phosphorylation and indirect inhibition of AChR function in seronegative MG. Neurology. 59:1672-1673.

82. Romi, F., Skeie, G.O., Gihus, N.E., and Aarli, J.A. 2005. Striational antibodies in myasthenia gravis: reactivity and possible clinical significance. Arch. Neurol. 62:442-446.

83. Mohan, S., Barohn, R.J., Jackson, C.E., and Krolick, K.A. 1994. Evaluation of myosin-reactive antibodies from a panel of myasthenia gravis patients. Clin. Immunol. Immunopathol. 70:266-273.

84. Aarli, J.A. 2001. Titin, thymoma, and myasthenia gravis. Arch. Neurol. 58:869-870.

85. Baggi, F., et al. 1998. Anti-titin and antiryanodine receptor antibodies in myasthenia gravis patients with thymoma. Ann. N. Y. Acad. Sci. 841:538-541.

86. Keesey, J.C. 2004. Clinical evaluation and management of myasthenia gravis. Muscle Nerve. 29:484-505

87. Katirii, B., and Kaminski, H.J. 2002. Electrodiagnostic approach to the patient with suspected neuromuscular junction disorder. Neurol. Clin. 20:557-586, viii.

88. [Anonymous]. 1992. Guidelines in electrodiagnostic medicine. American Association of Electrodiagnostic Medicine. Muscle Nerve. 15:229-253.

89. Soreq, H., and Seidman, S. 2001. Acetylcholinesterase-new roles for an old actor. Nat. Rev. Neurosci. 2:294-302.

90. Brenner, T., et al. 2003. The role of readthrough acetylcholinesterase in the pathophysiology of myasthenia gravis. FASEB J. 17:214-222.

91. Bedlack, R.S., and Sanders, D.B. 2002. Steroid treatment for myasthenia gravis: steroids have an important role. Muscle Nerve. 25:117-121.

92. Lindner, A., Schalke, B., and Toyka, K.V. 1997. Outcome in juvenile-onset myasthenia gravis: a retrospective study with long-term follow-up of 79 patients. J. Neurol. 244:515-520.

93. Palace, J., Newsom-Davis, J., and Lecky, B. 1998. A randomized double-blind trial of prednisolone alone or with azathioprine in myasthenia gravis. Myasthenia Gravis Study Group. Neurology. 50:1778-1783

94. Spring, P.J., and Spies, J.M. 2001. Myasthenia gravis: options and timing of immunomodulatory treatment. BioDrugs. 15:173-183.

95. Tindall, R.S., et al. 1987. Preliminary results of a double-blind, randomized, placebo-controlled trial of cyclosporine in myasthenia gravis. N. Engl. J. Med. 316:719-724.

96. Tindall, R.S., Phillips, J.T., Rollins, J.A., Wells, L., and Hall, K. 1993. A clinical therapeutic trial of cyclosporine in myasthenia gravis. Ann. N. Y. Acad. Sci. 681:539-551.

97. Ponseti, J.M., et al. 2005. Benefits of FK506 (tacrolimus) for residual, cyclosporin- and prednisoneresistant myasthenia gravis: one-year follow-up of an open-label study. Clin. Neurol. Neurosurg. 107:187-190.

98. Ciafaloni, E. 2005. Mycophenolate mofetil and myasthenia gravis. Lupus. 14(Suppl. 1):s46-s49.

99. Chaudhry, V., Cornblath, D.R., Griffin, J.W., O’Brien, R., and Drachman, D.B. 2001. Mycophenolate mofetil: a safe and promising immunosuppressant in neuromuscular diseases. Neurology. 56:94-96.

100. Drachman, D.B., Jones, R.J., and Brodsky, R.A. 2003 Treatment of refractory myasthenia: "rebooting" with high-dose cyclophosphamide. Ann. Neurol. 53:29-34.

101.Pescovitz, M.D. 2006. Rituximab, an anti-cd20 monoclonal antibody: history and mechanism of action. Am. J. Transplant. 6:859-866.

102.Tuzun, E., Meriggioli, M.N., Rowin, J., Yang, H., and Christadoss, P. 2005. Myasthenia gravis patients with low plasma IL-6 and IFN-gamma benefit from etanercept treatment. J. Autoimmun. 24:261-268.

103.Newsom-Davis, J. 2003. Therapy in myasthenia gravis and Lambert-Eaton myasthenic syndrome. Semin. Neurol. 23:191-198.

104.Samuelsson, A., Towers, T.L., and Ravetch, J.V. 2001. Anti-inflammatory activity of IVIG mediated through the inhibitory Fc receptor. Science. 291:484-486.

105.Psaridi-Linardaki, L., Trakas, N., Mamalaki, A., and Tzartos, S.J. 2005. Specific immunoadsorption of the autoantibodies from myasthenic patients using the extracellular domain of the human muscle acetylcholine receptor alpha-subunit. Development of an antigen-specific therapeutic strategy. J. Neuroim munol. 159:183-191.

106.Gronseth, G.S., and Barohn, R.J. 2000. Practice parameter: thymectomy for autoimmune myasthenia gravis (an evidence-based review): report of the Quality Standards Subcommittee of the American Academy of Neurology. Neurology. 55:7-15.

107.Jaretzki, A., Steinglass, K.M., and Sonett, J.R. 2004. Thymectomy in the management of myasthenia gravis. Semin. Neurol. 24:49-62.

108.Wolfe, G.I., Kaminski, H.J., Jaretzki, A., 3rd, Swan, A., and Newsom-Davis, J. 2003. Development of a thymectomy trial in nonthymomatous myasthenia gravis patients receiving immunosuppressive therapy. Ann. N. Y. Acad. Sci. 998:473-480.

109.Jaretzki, A., 3rd, et al. 2000. Myasthenia gravis: recommendations for clinical research standards. Task Force of the Medical Scientific Advisory Board of the Myasthenia Gravis Foundation of America.
Neurology. 55:16-23

110.Patel, M.R., and Granger, C.B. 2005. Pexelizumab: a novel therapy for myocardial ischemia-reperfusion. Drugs Today (Barc.). 41:165-170.

111.Fitch, J.C., et al. 1999. Pharmacology and biological efficacy of a recombinant, humanized, single-chain antibody C5 complement inhibitor in patients undergoing coronary artery bypass graft surgery with cardiopulmonary bypass. Circulation. 100:2499-2506.

112.Keshavjee, S., Davis, R.D., Zamora, M.R., de Perrot, M., and Patterson, G.A. 2005. A randomized, placebo-controlled trial of complement inhibition in ischemia-reperfusion injury after lung transplantation in human beings. J. Thorac. Cardiovasc. Surg. 129:423-428.

113.Drachman, D.B., McIntosh, K.R., Reim, J., and Balcer, L. 1993. Strategies for treatment of myasthenia gravis. Ann. N. Y. Acad. Sci. 681:515-528.

114.Yarilin, D., Duan, R., Huang, Y.M., and Xiao, B.G. 2002. Dendritic cells exposed in vitro to TGF-beta1 ameliorate experimental autoimmune myasthenia gravis. Clin. Exp. Immunol. 127:214-219.

115.Adikari, S.B., Lian, H., Link, H., Huang, Y.M., and Xiao, B.G. 2004. Interferon-gamma-modified dendritic cells suppress B cell function and ameliorate the development of experimental autoimmune myasthenia gravis. Clin. Exp. Immunol. 138:230-236.

116.Duan, R.S., Adikari, S.B., Huang, Y.M., Link, H., and Xiao, B.G. 2004. Protective potential of experimental autoimmune myasthenia gravis in Lewis rats by IL-10-modified dendritic cells. Neurobiol. Dis. 16:461-467.

117. Karachunski, P.I., Ostlie, N.S., Okita, D.K., and Conti-Fine, B.M. 1997. Prevention of experimental myasthenia gravis by nasal administration of synthetic acetylcholine receptor $\mathrm{T}$ epitope sequences. J. Clin. Invest. 100:3027-3035.

118. Karachunski, P.I., Ostlie, N.S., Okita, D.K., Garman, R., and Conti-Fine, B.M. 1999. Subcutaneous administration of T-epitope sequences of the acetylcholine receptor prevents experimental myasthenia gravis. J. Neuroimmunol. 93:108-121.

119.Baggi, F., et al. 1999. Oral administration of an immunodominant T-cell epitope downregulates Th1/Th2 cytokines and prevents experimental myasthenia gravis. J. Clin. Invest. 104:1287-1295.

120.Xiao, B.G., and Link, H. 1997. Mucosal tolerance: a two-edged sword to prevent and treat autoimmune diseases. Clin. Immunol. Immunopathol. 85:119-128.

121.Urbatsch, I.L., Sterz, R.K., Peper, K., and Trommer, W.E. 1993. Antigen-specific therapy of experimental myasthenia gravis with acetylcholine receptor-gelonin conjugates in vivo. Eur. J. Immunol. 23:776-779.

122.Wu, J.M., Wu, B., Miagkov, A., Adams, R.N., and Drachman, D.B. 2001. Specific immunotherapy of experimental myasthenia gravis in vitro: the "guided missile" strategy. Cell. Immunol. 208:137-147.

123.Vandenbark, A.A., Vainiene, M., Celnik, B., Hashim, G., and Offner, H. 1992. TCR peptide therapy decreases the frequency of encephalitogenic $\mathrm{T}$ cells in the periphery and the central nervous system. J. Neuroimmunol. 39:251-260.

124.Cohen-Kaminsky, S., and Jambou, F. 2005. Prospects for a T-cell receptor vaccination against myasthenia gravis. Expert Rev. Vaccines. 4:473-492.

125.Dayan, M., et al. 2004. Immunomodulation by a dual altered peptide ligand of autoreactive responses to the acetylcholine receptor of peripheral blood lymphocytes of patients with myasthenia gravis. Hum. Immunol. 65:571-577.

126. Bromberg, M.B. 2005. Myasthenia gravis and myasthenic syndromes. In Motor disorders. D.S. Younger, editor. Lippincott Williams \& Wilkins. Philadelphia, Pennsylvania, USA. 231-246. 